\title{
Implementation of fuzzy logic method for automation of decision making of Boeing aircraft landing
}

\author{
Winda Pratiwi, Aghus Sofwan, Iwan Setiawan \\ Department of Electrical Engineering, Diponegoro University, Indonesia
}

\begin{tabular}{l}
\hline Article Info \\
\hline Article history: \\
Received Mar 6, 2020 \\
Revised May 22, 2021 \\
Accepted Jun 3, 2021 \\
\hline Keywords: \\
Aircraft \\
Fuzzy logic Mamdani \\
Landing \\
Pilot experience \\
Weather
\end{tabular}

\section{Corresponding Author:}

Winda Pratiwi

Department of Electrical Engineering

Diponegoro University, Semarang, Indonesia

Email: windapratiwi544@students.undip.ac.id

\begin{abstract}
In the landing process, airplanes have many safety factors that must be protected. Weather advice and information is very important as a consideration in determining the feasibility of landing an aircraft. The main objective of this research is the implementation of Mamdani fuzzy simulation in determining the feasibility of landing aircraft at Ahmad Yani Airport in Semarang using ATC police and pilot coordination on runway number 31. Wind direction, wind velocity, visibility, and pilot experience are used to determine eligibility aircraft landing. An intelligent system based on fuzzy logic produces three decisions that are feasible, careful, and not feasible in landing an aircraft on a runway. The results of the study concluded from an intelligent system based on fuzzy logic can be used to determine aircraft landing decisions on the runway of Ahmad Yani Airport Semarang on runway number 31 .
\end{abstract}

This is an open access article under the $\underline{C C B Y-S A}$ license.

\section{INTRODUCTION}

In modern times airplanes are both a means of transporting goods and humans that can shorten travel times, so they are often used to travel from one place to another in a much shorter time compared to using land or sea travel. The aircraft requires a high safety factor including the process when landing [1]-[7]. In the landing process of an aircraft, many factors must be considered such as the weather and pilot experience in controlling an aircraft [1], [3], [8]-[14]. In the landing process, an aircraft is assisted by an officer from the air traffic controller (ATC) whose duty is to guide the landing such as providing advice and information. This is useful for the safety and efficiency of air traffic control. ATC officers will provide information in the form of weather conditions on the runway such as wind velocity, wind direction, and visibility [8], [12], [14]-[17] to a pilot who will make an aircraft landing. A pilot can make a decision from this information whether a runway is appropriate to land an aircraft under certain weather conditions. pilot experience in operating the aircraft is also an important factor in landing decision making [18], [19]. During the aircraft landing process, a pilot and ATC officer require data information related to the latest weather conditions on the runway quickly and accurately to determine flight decisions. The information comes from BMKG (Meteorology, Climatology and Geophysics Agency). The information is processed by the ATC officer so that it can be informed to the pilot [1], [3], [14], [19]-[21]. The information is analyzed by the pilot so that it can be decision support in predicting the safety factor of landing an aircraft on a runway.

At present, there is a lot of research on aircraft landing decision making with several parameters used. One of them is titled "Take Off and Landing Prediction Using Fuzzy Logic" [15], in this study discussing decision making that helps ATC officers and pilots in making decisions whether a runway is 
appropriate to land or fly an aircraft with certain weather conditions. Some parameters used are visibility, wind direction, and wind speed. This research uses Mamdani fuzzy logic. The results of the decision are divided into feasible, careful, and not feasible for landing and take-off aircraft. The results of this research, show that this system can help ATC officers and pilots to make landing and flight decisions more quickly.

By referring to some journal results, using the concept of fuzzy logic is easier and the results are quite accurate. This study aims to produce a simulation of landing decision making systems based on the expertise of the ATC officer and a pilot. This research was carried out on runway number 31 an aircraft at Ahmad Yani Airport in Semarang [22]. In this study, Mamdani's fuzzy logic intelligent system is used to describe problems regarding weather and pilot experience in landing aircraft that contain uncertainties that can be applied in the decision making process [23]-[25]. In this research, the weather parameters used are wind velocity, wind direction, visibility, and pilot experience. Fuzzy intelligent systems can describe, know, and model human thought processes and design a system so that it can mimic human behavior. With the fuzzy process which consists of fuzzification, inference, and defuzzification [25]-[28], it is expected that the level of truth in the decision of landing aircraft becomes more accurate.

At present, there is a lot of research on aircraft landing decision making with several parameters used. One of them is titled "A Practical Weather Forecasting for the Air Traffic Control System using Fuzzy Hierarchical Technique" [27]. This study discusses the weather prediction and decision making of an appropriate or unfit airport for landing or take-off of an aircraft with certain changing weather conditions. In this reference using the fuzzy logic Mamdani hierarchical technique. Each parameter that is owned is combined in a group to produce an intermediate output. Environmental parameters consist of wind velocity, visibility, and wind pressure. Turbulence parameters are sky conditions, thunderstorms, and precipitation. Finally, the fog parameters include air temperature, dew point, and humidity. The results of this study indicate that the output is very accurate in decisions about weather forecasts.

In the study "Prediction of Landing and Take-off of Aircraft based on the Weather Using Fuzzy Logic" [29] which discusses the decision making of an appropriate or unfit airport for landing or take-off an aircraft with changing weather conditions. In this research Mamdani fuzzy logic method with three parameters of wind speed, wind direction, and visibility. Wind velocity has a low membership function (0-5 knots), medium (3-13 knots), and high (10-30 knots). Wind direction has membership functions safe_1 $\left(0^{\circ}-\right.$ $\left.120^{\circ}\right)$, danger_1 $\left(100^{\circ}-180^{\circ}\right)$, safe_2 $\left(160^{\circ}-300^{\circ}\right)$, danger_2 $\left(280^{\circ}-360^{\circ}\right)$, and safe_3 $\left(340^{\circ}-360^{\circ}\right)$. Visibility has close membership functions $(100-1100 \mathrm{~m})$, medium $(1000-7000 \mathrm{~m})$, and far $(6000-10000 \mathrm{~m})$. The decision of airport conditions with certain weather is suitable, careful, and not suitable in percentage level. The results of this study the system can provide appropriate landing and flight decisions.

In the study "Fuzzy Logic Approach To Airplane Precision Instrument Approach And Landing" [19] which discusses the simulation using Microsoft flight simulator to estimate the success rate of landing or take-off an aircraft with certain weather conditions and pilot experience. In this study using the ANFIS method, using the backpropagation method to train FIS, in this study there were three parameters used, namely wind speed, visibility, and pilot experience. Wind speed has a membership function of low (20-60 knots), average (40-80 knots), high (60-100 knots), and very high (80-120 knots). Visibility has very low membership functions $(0-5 \mathrm{~km})$, low $(0-10 \mathrm{~km})$, medium $(5-15 \mathrm{~km})$, and high $(10-20 \mathrm{~km})$. Pilot experience has a membership function of low (0-2000 hours) and high (500-2000 hours). The results of this study the system can estimate the success rate of a landing and take-off accordingly.

Fuzzy logic is an enhancement of Boolean logic that deals with the concept of partial truth. Boolean logic states that everything can be expressed in binary terms ( 0 or 1 , yes or no), fuzzy logic is used to replace Boolean logic. Fuzzy logic allows membership values between 0 and 1 to be depicted in the form of uncertainty concepts such as uncertainty such as "little", "not bad", and "very". Some aspects of the real world always or usually are outside the mathematical model and are inexact. The concept of uncertainty is the beginning of the basic concept of the emergence of the concept of fuzzy logic. The originator of the idea of fuzzy logic is Prof. Dr. Lotfi Zadeh from the University of California, Berkeley in 1965. In principle, the fuzzy set is the expansion of the crisp set, which is a set that divides a group of individuals into two categories, namely members and non-members [4], [8], [23], [26], [28].

\section{RESEARCH METHOD}

To identify like a plane landing on a runway with certain weather conditions and pilot experience, a fuzzy logic method that has 4 parameters is used, consisting of wind velocity, wind direction, visibility, and pilot experience. This parameter has a relationship between data variables and aircraft landing decisions based on previous research on landing aircraft. All variables in each criterion will be processed using fuzzy logic. Fuzzy logic has three stages, namely fuzzification, system inference, and defuzzification. Fuzzification is the process of mapping crisp input values derived from a controlled system by the fuzzy set membership 
function. Furthermore, the system inference process will process the fuzzification output determined by fact data from experts or institutions and presented in logical sentences in the form of rules. After calculating each variable, the final process is defuzzification. All combinations of variables or parameters will be compared by evaluating existing rules that result in decisions on landing aircraft.

Figure 1 is a system diagram and a detailed description of it is that the data used for fuzzy logic is data from AIRNAV Ahmad Yani Airport in Semarang. The crisp value of each input variable is then processed using fuzzy logic (fuzzification). Furthermore, from the results of the fuzzification, the process of reading or executing the existing rules is carried out. The input of the defuzzification process is a fuzzy set obtained from the composition of fuzzy rules, while the resulting output is a number in the fuzzy set domain. If a fuzzy set is given in a certain range, it must be able to take a certain crisp value as output.

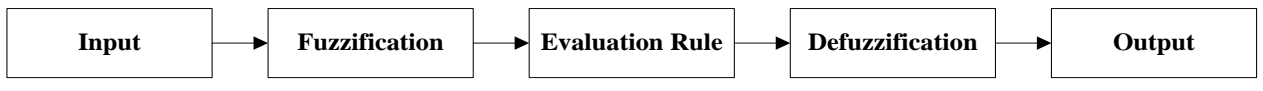

Figure 1. System design decision aircraft landing

\subsection{Fuzzification}

The linguistic values of each variable can be categorized from classification data based on the value of each variable. Table 1 shows the variables used in this study. Each variable value has been determined based on previous research [19], [27], [29] and a book titled Airplane Flying Handbook Issued by the Federal Aviation Administration [11]. The linguistic values represented in graphic form are shown in Figures 2 to 5.

Table 1. Value of linguistic variables

\begin{tabular}{cccc}
\hline No & Variable & \multicolumn{2}{c}{ Criteria } \\
\hline \multirow{3}{*}{1} & Wind Velocity (Knots) & $3-13$ & Low \\
& & $10-30$ & Average \\
& & $0-70$ & High \\
& & $60-90$ & Danger 1 \\
2 & Wind Direction (Degree) & $80-180$ & Safively Safe 1 \\
& & $170-200$ & Relatively Safe 2 \\
& & $190-360$ & Danger 2 \\
& & $7500-10000$ & Far \\
3 & Visibility (Meters) & $4500-8000$ & Medium \\
& & $0-5000$ & Near \\
& & $500-2000$ & High \\
4 & Pilot Experience (Hours) & $0-2000$ & Low \\
\hline
\end{tabular}

\subsubsection{Wind velocity}

In the variable wind velocity, three fuzzy sets are defined, namely low, average, and high. To represent the wind speed variable, a trapezoid curve is used for the fuzzy low set and high, a triangle curve shape for the fuzzy average set. Figure 2 is a fuzzy set for the wind velocity variable.

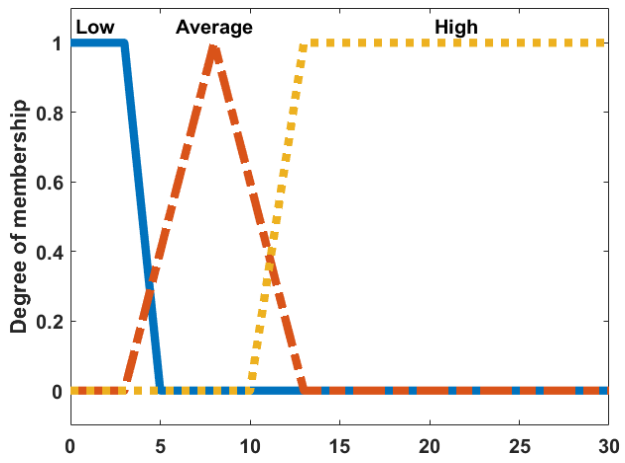

Figure 2. Wind velocity graph 


\subsubsection{Wind direction}

In the wind direction variable, five fuzzy sets are defined, namely danger 1, relatively safe 1, safe, relatively safe 2 , and danger 2 . To represent the wind direction variable a trapezoid curve is used for all fuzzy sets. Figure 3 is the fuzzy set for the wind direction variable. Wind direction and win velocity are closely related and will affect the landing of the aircraft because it will produce a crosswind [11], [17].

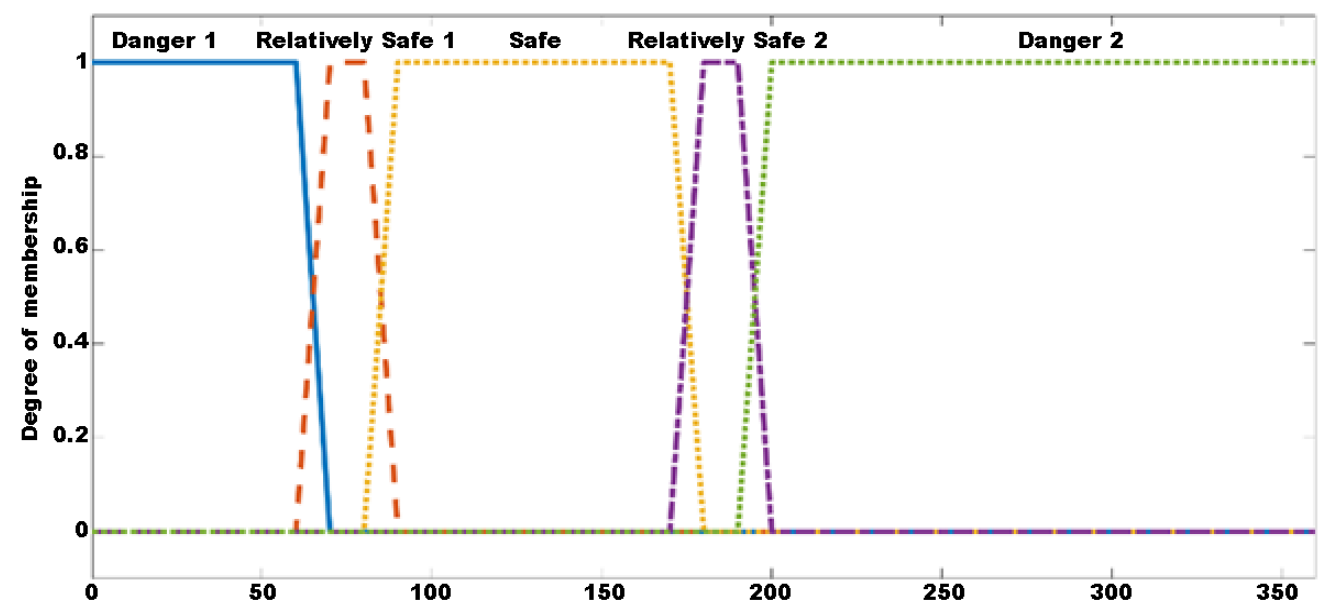

Figure 3. Wind direction graph

\subsubsection{Visibility}

In the visibility variable three fuzzy sets are defined, namely near, medium, and far. To represent the visibility variable the trapezoid curve is used for the fuzzy near set, and far, the triangle curve shape for the fuzzy set is rather clear. Figure 4 is a fuzzy set for the visibility variable.

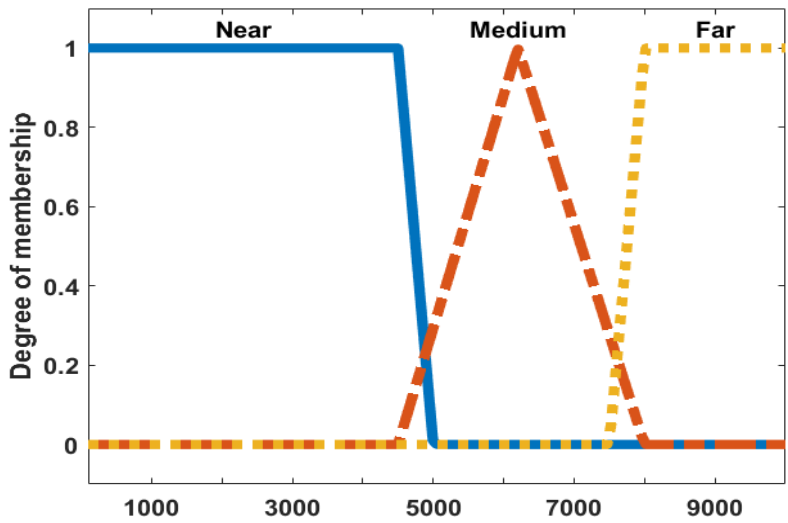

Figure 4. Visibility graph

\subsubsection{Pilot experience}

In the pilot experience variable, two fuzzy sets are defined, namely low, and high. To represent the pilot hour flight variable the triangular curve is used for both fuzzy sets. Figure 5 is a fuzzy set for the pilot experience variable. 


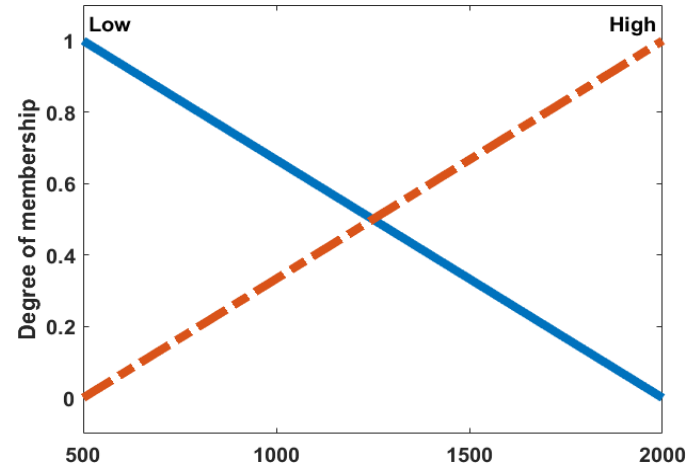

Figure 5. Pilot experience graph

\subsection{Evaluation rules}

References and guidelines for determining evaluation rules are shown in Table 2. These evaluation rules were developed based on the rule approach and correlation calculation to find the priority of variables. Thus, after the process, evaluation rules are developed into 25 evaluation rules.

Table 2. Evaluation rule

\begin{tabular}{|c|c|c|c|c|c|}
\hline $\mathrm{No}$ & Wind velocity & Wind direction & Visibility & Pilot experience & Aircraft landing \\
\hline 1 & Low & Safe & Medium & Low & Feasible \\
\hline 2 & Low & Danger 2 & Medium & Low & Careful \\
\hline 3 & Low & Danger 2 & Medium & High & Feasible \\
\hline 4 & Low & Danger 2 & Medium & High & Feasible \\
\hline 5 & Low & Danger 2 & Medium & High & Feasible \\
\hline 6 & Low & Danger 2 & Medium & High & Feasible \\
\hline 7 & Low & Danger 2 & Medium & High & Feasible \\
\hline 8 & Low & Safe & Medium & Low & Feasible \\
\hline 9 & Low & Danger 2 & Medium & High & Feasible \\
\hline 10 & Low & Safe & Medium & High & Feasible \\
\hline 11 & Low & Danger 2 & Medium & High & Feasible \\
\hline 12 & Low & Safe & Medium & High & Feasible \\
\hline 13 & Average & Relatively Safe 2 & Medium & High & Feasible \\
\hline 14 & Low & Danger 2 & Medium & High & Feasible \\
\hline 15 & Average & Danger 2 & Medium & Low & Not Feasible \\
\hline 16 & Average & Danger 2 & Medium & Low & Not Feasible \\
\hline 17 & Average & Danger 2 & Medium & High & Careful \\
\hline 18 & High & Danger 2 & Medium & High & Not Feasible \\
\hline 19 & Average & Danger 2 & Medium & High & Careful \\
\hline 20 & Average & Danger 2 & Far & High & Careful \\
\hline 21 & High & Danger 2 & Far & Low & Not Feasible \\
\hline 22 & High & Danger 2 & Far & High & Careful \\
\hline 23 & High & Danger 2 & Far & High & Careful \\
\hline 24 & High & Danger 2 & Far & High & Careful \\
\hline 25 & High & Danger 2 & Far & High & Careful \\
\hline
\end{tabular}

\subsection{Defuzzification}

In this defuzzification process, it is used to find fuzzy membership. From each variable such as wind velocity, wind direction, visibility, and pilot experience. The five variables will be obtained as the output level from a combination of variables that have been calculated using fuzzy logic. There are 3 classifications of output levels: feasible, careful, and not feasible.

\section{RESULTS AND ANALYSIS}

In this section, we provide measurable results for fuzzy logic calculations. Calculations have been made on 25 data from AIRNAV Ahmad Yani Airport Semarang to represent some of the rules that have been made. Table 3 is the data used in this study and the results of real probabilities and system probabilities. 
Table 3. Data measurement and comparison of data results

\begin{tabular}{|c|c|c|c|c|c|c|}
\hline No & Wind Velocity & Wind Direction & Visibility & Pilot Experience & Real Probability & System Probability \\
\hline 1 & 2 & 100 & 6000 & 450 & Feasible & Feasible \\
\hline 2 & 2 & 210 & 6000 & 450 & Careful & Careful \\
\hline 3 & 2 & 200 & 6000 & 1000 & Feasible & Careful \\
\hline 4 & 0.8 & 220 & 6000 & 1000 & Feasible & Careful \\
\hline 5 & 2 & 230 & 6000 & 1500 & Feasible & Careful \\
\hline 6 & 2 & 260 & 6000 & 2000 & Feasible & Feasible \\
\hline 7 & 3 & 260 & 6000 & 2000 & Feasible & Feasible \\
\hline 8 & 2 & 130 & 6000 & 450 & Feasible & Feasible \\
\hline 9 & 0.8 & 210 & 6000 & 1000 & Feasible & Careful \\
\hline 10 & 2 & 160 & 6000 & 1000 & Feasible & Feasible \\
\hline 11 & 2 & 210 & 5000 & 1500 & Feasible & Careful \\
\hline 12 & 2 & 160 & 5000 & 1500 & Feasible & Feasible \\
\hline 13 & 3 & 170 & 5000 & 2000 & Feasible & Feasible \\
\hline 14 & 2 & 260 & 6000 & 2000 & Feasible & Feasible \\
\hline 15 & 4 & 300 & 6000 & 450 & Not Feasible & Careful \\
\hline 16 & 6 & 300 & 7000 & 450 & Not Feasible & Not Feasible \\
\hline 17 & 9 & 310 & 7000 & 1000 & Careful & Not Feasible \\
\hline 18 & 10 & 310 & 7000 & 1000 & Not Feasible & Not Feasible \\
\hline 19 & 9 & 330 & 7000 & 2000 & Careful & Careful \\
\hline 20 & 8 & 300 & 8000 & 2000 & Careful & Careful \\
\hline 21 & 13 & 310 & 8000 & 450 & Not Feasible & Not Feasible \\
\hline 22 & 12 & 310 & 8000 & 1000 & Careful & Not Feasible \\
\hline 23 & 14 & 310 & 8000 & 1000 & Careful & Not Feasible \\
\hline 24 & 10 & 300 & 8000 & 2000 & Careful & Careful \\
\hline 25 & 12 & 310 & 8000 & 2000 & Careful & Careful \\
\hline
\end{tabular}

Graphic user interface (GUI) is a graphical display medium as a substitute for text commands for user interaction. Figure 6 is a GUI for the implementation of fuzzy logic method for automation of decision making of Boeing aircraft landing.

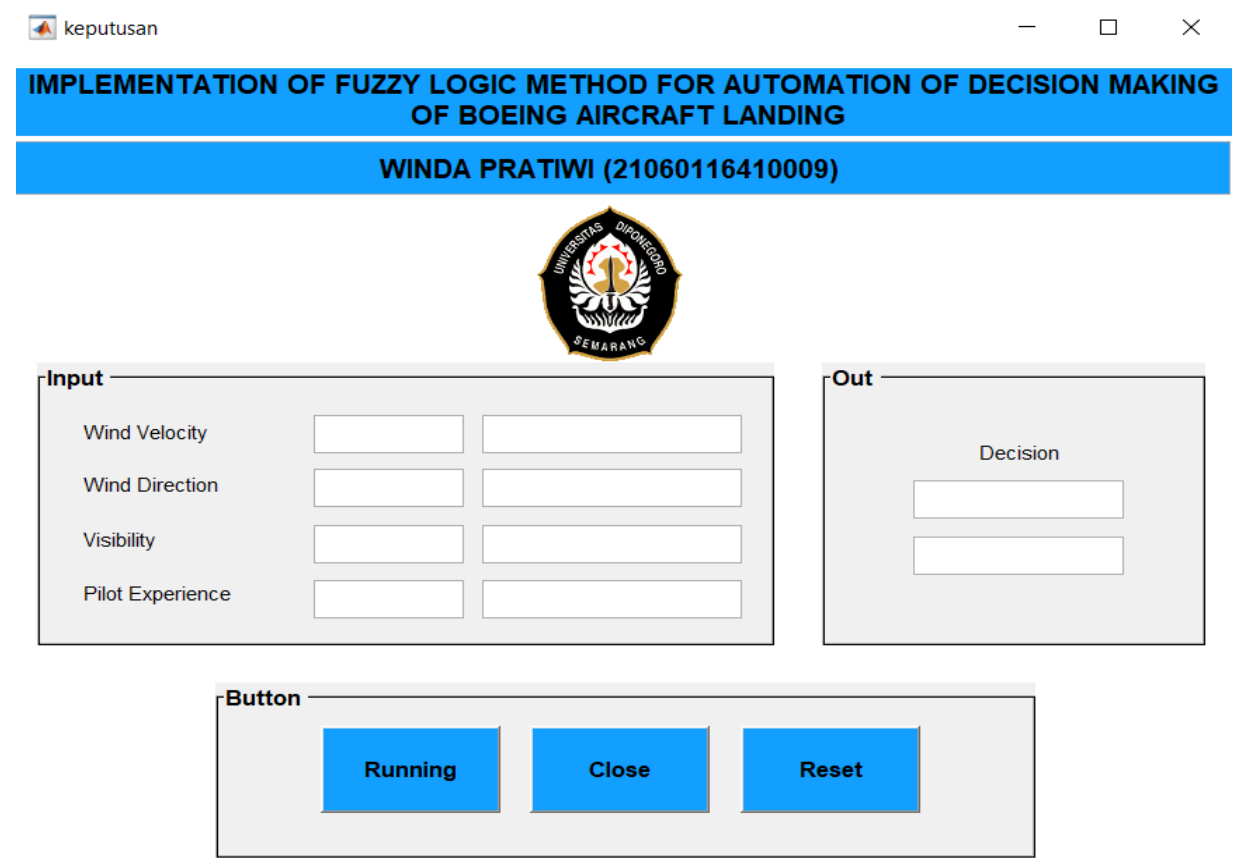

Figure 6. Graphical user interface of aircraft landing decision using Mamdani fuzzy logic

\section{CONCLUSION}

This paper presents the proposed fuzzy logic for intelligent aircraft landing decision systems. Several factors that can affect aircraft landing decisions required in this method include wind velocity, wind 
direction, visibility, and pilot experience. The landing decision is divided into three classifications, which are feasible, careful, and not feasible. The results of aircraft landing decisions use fuzzy logic compared to real results. There are 25 data collected from AIRNAV Ahmad Yani Airport in Semarang, there are 9 different data results. This difference is not very far because of the difference between the real probability and system probability. So, it can be said that the fuzzy logic system works quite well. In the future, it is expected that research related to the parameters added air density, humidity, and precipitation. Pilots and ATC officers are greatly helped by the existence of an airplane landing system.

\section{ACKNOWLEDGEMENTS}

The author would like to thank AIRNAV Ahmad Yani Airport Semarang for the support by providing data sources.

\section{REFERENCES}

[1] E. Mangortey, O. J. Pinon, T. G. Puranik, and D. N. Mavris, "Predicting the Occurrence of Weather and Volume Related Ground Delay Programs," no. June, pp. 1-29, 2019, doi: 10.2514/6.2019-3188.

[2] C. Wang and F. Holzapfel, "Modeling of the aircraft landing behavior for runway excursion and abnormal runway contact analysis," AIAA Model. Simul. Technol. Conf. 2018, no. 209959, pp. 1-9, 2018, doi: 10.2514/6.2018-1166.

[3] N. K. Ragbir, B. S. Baugh, S. Rice, and S. R. Winter, "How Nationality, Weather, Wind, and Distance Affect Consumer Willingness to Fly in Autonomous Airplanes," J. Aviat. Technol. Eng., vol. 8, no. 1, pp. 2-10, 2018, doi: 10.7771/2159-6670.1180.

[4] D. K. Chaturvedi, R. Chauhan, and P. K. Kalra, "Application of generalised neural network for aircraft landing control system," Soft Comput. - A Fusion Found. Methodol. Appl., vol. 6, no. 6, pp. 441-448, 2002, doi: 10.1007/s00500-001-0159-1.

[5] R. Lungu and M. Lungu, "Automatic landing system using neural networks and radio-technical subsystems," Chinese J. Aeronaut., vol. 30, no. 1, pp. 399-411, 2017, doi: 10.1016/j.cja.2016.12.019.

[6] H. Baomar and P. J. Bentley, "Autonomous navigation and landing of large jets using Artificial Neural Networks and learning by imitation,” 2017 IEEE Symp. Ser. Comput. Intell. SSCI 2017 - Proc., vol. 2018-Janua, pp. 1-10, 2018, doi: 10.1109/SSCI.2017.8280916.

[7] D. Fitzgerald and R. Walker, "Classification of Candidate Landing Sites for UAV Forced Landings," no. August, pp. 1-13, 2005.

[8] X. Su, Y. Wu, J. Song, and P. Yuan, "A fuzzy path selection strategy for aircraft landing on a carrier," Appl. Sci., vol. 8, no. 5, 2018, doi: 10.3390/app8050779.

[9] T. T. Takahashi and R. E. Perez, "On the Operational Implications of Traditional Design Rules for Minimum Controllable Airspeed," no. January, pp. 1-25, 2020, doi: 10.2514/6.2020-0749.

[10] Y. Pang, H. Yao, J. Hu, and Y. Liu, "A Recurrent Neural Network Approach for Aircraft Trajectory Prediction with Weather Features from Sherlock,” no. June, pp. 1-14, 2019, doi: 10.2514/6.2019-3413.

[11] Federal Aviation Administration, "Airplane Flying Handbook," U.S. Dep. Transp., p. 348, 2016, doi: https://www.faa.gov/regulations_policies/handbooks_manuals/aircraft/airplane_handbook/media/FAA-H-80833B.pdf.

[12] F. Sadjadi and S. Member, "Radar Synthetic Vision System for Adverse Weather Aircraft Landing," vol. 35, no. 1, 1999.

[13] T. T. Fujita and F. Caracena, "An Analysis of Three Weather-Related Aircraft Accidents," vol. 58, no. 11, 1977.

[14] W. Wong, C. Lau, and P. Chan, "Aviation Model: A Fine-Scale Numerical Weather Prediction System for Aviation Applications at the Hong Kong International Airport," vol. 2013, 2013.

[15] R. F. Wijaya, Y. M. Tondang, and A. P. U. Siahaan, "Take Off and Landing Prediction using Fuzzy Logic," Int. J. Recent Trends Eng. Res., vol. 2, no. 12, pp. 127-134, 2016.

[16] S. K. Ku and S. M. Hong, "Deep neural network for runway visual range estimation," Int. J. Appl. Eng. Res., vol. 12, no. 22, pp. 11862-11864, 2017.

[17] H. Baomar and P. J. Bentley, "Autonomous landing and go-around of airliners under severe weather conditions using Artificial Neural Networks," 2017 Work. Res. Educ. Dev. Unmanned Aer. Syst. RED-UAS 2017, no. April, pp. 162-167, 2017, doi: 10.1109/RED-UAS.2017.8101661.

[18] I. Gultepe et al., "A Review of High Impact Weather for Aviation Meteorology," Pure Appl. Geophys., vol. 176, no. 5, pp. 1869-1921, 2019, doi: 10.1007/s00024-019-02168-6.

[19] V. T. Zadeh, "Fuzzy logic approach to airplane precision instrument approach and landing," ARPN J. Eng. Appl. Sci., vol. 7, no. 4, pp. 423-431, 2012.

[20] H. Wang, D. Gong, and R. Wen, "Air traffic controllers workload forecasting method based on neural network," Proc. 2015 27th Chinese Control Decis. Conf. CCDC 2015, vol. 161, pp. 2460-2463, 2015, doi: 10.1109/CCDC.2015.7162334.

[21] Y. Liu, J. Zhang, W. Wang, and D. Zhao, "Fuzzy synthetic assessment of air traffic controllers situational awareness based on short-term memory measurement," Proc. 2012 4th Int. Conf. Intell. Human-Machine Syst. Cybern. IHMSC 2012, vol. 2, pp. 119-122, 2012, doi: 10.1109/IHMSC.2012.125.

[22] E. Turban and L. E. Frenzel, Expert System and Applied Artificial. New York: Macmillan Publishing Company, 1992.

Implementation of fuzzy logic method for automation of decision making of... (Winda Pratiwi) 
[23] L. A. Zadeh, I. Introduction, and U. S. Navy, "Fuzzy Sets * -," vol. 353, pp. 338-353, 1965.

[24] G. J. Klir and B. O. Yuan, Fuzzy Sets and Fuzzy Logic Theory and Applications. New Jersey: Prentice Hall, 1995.

[25] T. J. Ross, Fuzzy Logic with Engineering and Applications, Third. University of New Mexico USA.: Wiley, 2010.

[26] M. D. Wardhana, A. Sofwan, and I. Setiawan, "Fuzzy Logic Method Design for Landslide Vulnerability," vol. 3004, no. 2019 , pp. 1-6, 2019.

[27] A. A. Ramli, M. R. Islam, M. F. M. Fudzee, M. A. Salamat, and S. Kasim, "A Practical Weather Forecasting for Air Traffic Control System using Fuzzy Hierarchical Technique," Adv. Intell. Syst. Comput., vol. 287, no. January, 2014, doi: 10.1007/978-3-319-07692-8.

[28] B. K. Hansen, "A fuzzy logic-based analog forecasting system for ceiling and visibility," Weather Forecast., vol. 22, no. 6, pp. 1319-1330, 2007, doi: 10.1175/2007WAF2006017.1.

[29] R. Rahim, "Prediction of landing and take-off of aircraft based on the weather using fuzzy logic," IJAST, vol. 28, no. 20 , pp. 409-415, 2019.

\section{BIOGRAPHIES OF AUTHORS}

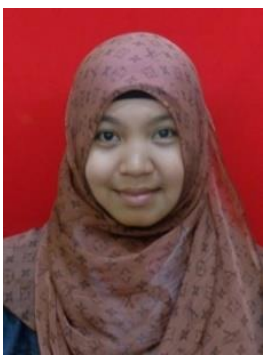

Winda Pratiwi is work for Airnav Indonesia. She is a technician for telecommunication, navigation, and surveillance in Ahmad Yani Airport. She graduated from Electrical engineering, Semarang University 2015.

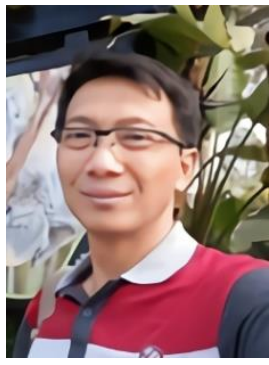

Aghus Sofwan is from Department of Electrical Engineering Diponegoro University, Indonesia. He graduated from Electrical Engineering, Diponegoro University and Gadjah Mada University, for undergraduate and master program, respectively. Furthermore, he graduated for doctoral program from King Saud University. Currently, he conducts researches in information technology fields, such as artificial intelligence, IoT, and big data analytics.

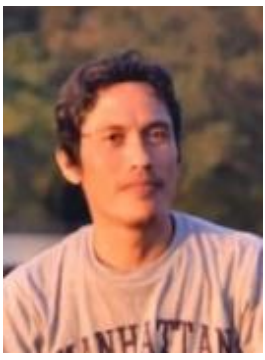

Iwan Setiawan is from the Department of Electrical Engineering at Diponegoro University, Indonesia. He Completion of Bachelor and Master Studies was completed in 1998 and 2003 at the Electrical Engineering University of Gadjah Mada, Yogyakarta with a specialization in the Control and Instrumentation System. Since 2012 he has been studying for a doctoral level at the Electrical Engineering Sepuluh November Institute of Technology, Surabaya. The area that I explore is primarily the design of an inverter or converter control system for renewable energy-based electricity generation applications. 